\title{
Climate change literacy and migration potential: micro-level evidence from Africa
}

\author{
Marc Helbling $^{1}\left(\mathbb{D} \cdot\right.$ Daniel Auer $^{1} \cdot$ Daniel Meierrieks $^{2} \cdot$ Malcolm Mistry $^{3,4} \mathbb{D}$. \\ Max Schaub ${ }^{5}$
}

Received: 31 March 2021 / Accepted: 2 October 2021/Published online: 6 November 2021

(c) The Author(s) 2021

\begin{abstract}
While a growing literature studies the effects of climate change on international migration, still only relatively little is known about the individual mechanisms linking migration decisions to climate change. We argue that climate change literacy (i.e., knowledge about climate change) is a major determinant of why some individuals consider migrating to other countries in response to climate change effects. In particular, climate change literacy helps individuals translate their perceptions of temperature changes into an understanding of these changes' irreversible long-term consequences. We test this hypothesis using highly accurate geo-coded data for 37,000 individuals across 30 African countries. We show that climate change indeed leads to stronger migration intentions among climate literates only. Furthermore, we show that climate change only increases migration intentions among climate literates when it is approximated by long-run increases in local temperatures, but not when operationalized as changing heat wave or precipitation patterns. Further analyses show that climate literates are more likely to live in urban areas, have a higher news consumption, are highly educated, and have demanding occupations. Consequently, climate change may further deprive affected countries of valuable talent.
\end{abstract}

Keywords International migration $\cdot$ Migration intentions $\cdot$ Climate change $\cdot$ Climate change literacy $\cdot$ Africa

\section{Introduction}

There is overwhelming evidence that the Earth's climate is warming, which in turn adversely affects natural systems and human living conditions (IPCC, 2014). For instance, global warming impairs agricultural production and economic growth, adversely affects

Marc Helbling

helbling@uni-mannheim.de

University of Mannheim, Mannheim, Germany

2 WZB Berlin Social Science Center, Berlin, Germany

3 Ca' Foscari University of Venice, Venice, Italy

4 The London School of Hygiene \& Tropical Medicine (LSHTM), London, UK

5 University of Hamburg, Hamburg, Germany 
human health, and can, under certain circumstances, fuel violent conflict (e.g., Haines et al. 2006; Dell et al., 2012; Carter et al. 2018; Abel et al. 2019; Mach et al. 2019; Vesco et al. 2021; Meierrieks, 2021). As a reaction to the adverse effects of global warming, people may leave their homes in increasing numbers and move abroad. Indeed, a number of studies suggest that climate change, especially in the form of rising temperatures, can affect international migration, even though the direction and strength of the estimated effects is often found to be context-dependent (e.g., Marchiori et al., 2012; Backhaus et al., 2015; Coniglio and Pesce, 2015; Cattaneo and Peri, 2016; Maurel and Tuccio, 2016; Berlemann and Steinhardt, 2017; Cattaneo et al., 2019; for contrary evidence see, e.g., Beine and Parsons, 2015). For instance, Cattaneo and Peri (2016) find that higher temperatures induce international migration in middle-income countries, while they reduce the probability of international migration in poor countries due to the presence of severe liquidity constraints.

Many studies correlate climate and migration data at the country level. This makes them vulnerable to the ecological fallacy, meaning that aggregate correlations may not hold at the individual level. For instance, finding that temperature rise lead to less international migration from poor countries (as in Cattaneo and Peri, 2016) does not necessarily imply that poor individuals are less likely to emigrate; it could also be the case that temperature rise affect the migration decisions of relatively rich individuals in comparatively poor countries. Consequently, this calls for individual level analyses to complement the empirical evidence on the nexus between climate change and migration at the country level.

Existing studies attempting to provide evidence for the climate change-migration nexus at the individual level have often relied on either data from single countries or self-reported perceptions of climate change, especially in the African context (e.g., Koubi et al., 2016a, 2016b; DeLongueville et al. 2020; Bekaert et al. 2021for a methodological overview, see Piguet 2010). ${ }^{1}$ We add to these studies by relating highly accurate geo-coded data measuring climate change at the local level (e.g., approximated by long-run increases in local temperatures) to individual migration intentions for 37,000 individuals across 30 African countries.

A potential obvious disadvantage of studying migration intentions is that not every intention to leave materializes, while other people who did not hold intentions might still move. Research has shown, however, that there is a strong association between emigration intentions and out-migration, suggesting that the former is indeed a useful proxy for the latter when out-migration is not directly measured: Tjaden et al. (2019) find a strong correlation between both variables at the country level, while Lu (1999) reports a similar relationship using individual data, albeit with greater variation. That is, while not all individuals who wish to emigrate will act on their plan (e.g., because of unobserved impeding factors), using migration intentions gives us a better idea of the migration potential as an upper bound of migration induced by climate change literacy under climate change (see also Docquier et al. 2014).

When studying how climate change affects individual migration intentions, we focus on the role of individual climate change literacy, i.e., knowledge about climate change and its long-term consequences. The role of climate change literacy has been hitherto unappreciated in the fields of climate change and migration. Here, we argue that this literacy is a major determinant of why people develop intentions to migrate especially internationally as a reaction to rising temperatures. In order for climate change to affect migration

\footnotetext{
1 See Koubi et al. (2016c) for an example that investigates both the effects of perceived and real climate change.
} 
intentions, individuals need to not only perceive the consequences of climate change but also understand its broader implications. Climate change literacy, similar to the effects of political knowledge (Galston, 2001: 223), helps people understand the impact of climate change on one's interests and life situation, constituting a key element of instrumental rationality (e.g., Delli Carpini and Keeter, 1996). Knowledge of climate change helps individuals translate a cognitive judgment (i.e., perceptions of temperature changes) into an evaluative judgment (i.e., an understanding of the long-term consequences) (see Marquis, 2010).

Such knowledge is especially valuable given the incremental nature of climate change and the associated slow onset of environmental degradation. By contrast, even though sudden or rapid-onset environmental changes (e.g., ex. hurricanes, typhoons, or landslides) are also expected to induce migration, we anticipate climate change literacy to play no major role in this context. This is because under these circumstances, people are forced to leave their home regions simply because they have no choice and not because they understand the broader implications. These events most often lead to temporary moves over short distances in order to be able to return soon. Cattaneo et al. (2019: 194) call this "survival migration."

It has been shown that a considerable number of individuals are not climate literate: for instance, approximately $40 \%$ of Africans have never heard of climate change, and only about $30 \%$ have some basic knowledge about its causes and negative effects (Selormey et al., 2019: 8, 12). The importance of climate change literacy, also in the context of climate change-induced international migration, is however no longer a fringe topic in African politics. An example is Uganda, which is investing into climate change education, having adopted a National Adaptation Programme of Action in 2007 and opened climate change information centers in rural areas in 2015. There are also calls to include climate change education into the national school curriculum (Nyasimi et al., 2016; Kasumba, 2020). What is more, local newspapers are increasingly pointing to linkages between natural calamities and climate change; for example, they link the drying up of water bodies to global warming and argue that this change is likely to be permanent (Buyondo, 2021). Similarly, in Zambia, climate change, and especially its impact on agriculture, has become a core policy issue that features regularly in the president's speeches (Lungu, 2019). Finally, in Kenya, climate change has recently been acknowledged as a primary cause of forced migration by the country's president (Kenyatta, 2021).

\section{Data and methods}

We test our hypothesis by relating migration, meteorological, and climate change literacy data for 37,000 individuals surveyed in 30 African countries between September 2016 and September 2018 to climate change occurring in the respondents' home location measured at a $0.25 * 0.25^{\circ}$ grid resolution. $^{2}$

As shown in Fig. 1, there is substantial within-country climate variation in the African countries we consider; this variation is linked to higher temperatures compared to

\footnotetext{
2 The 30 African countries in our sample are Benin, Botswana, Burkina Faso, Cameroon, Côte d'Ivoire, Eswatini, Gabon, Gambia, Ghana, Guinea, Kenya, Lesotho, Liberia, Madagascar, Malawi, Mali, Mozambique, Namibia, Niger, Nigeria, Senegal, Sierra Leone, South Africa, Sudan, Tanzania, Togo, Tunisia, Uganda, Zambia, and Zimbabwe. See Fig. 1 for interview locations.
} 


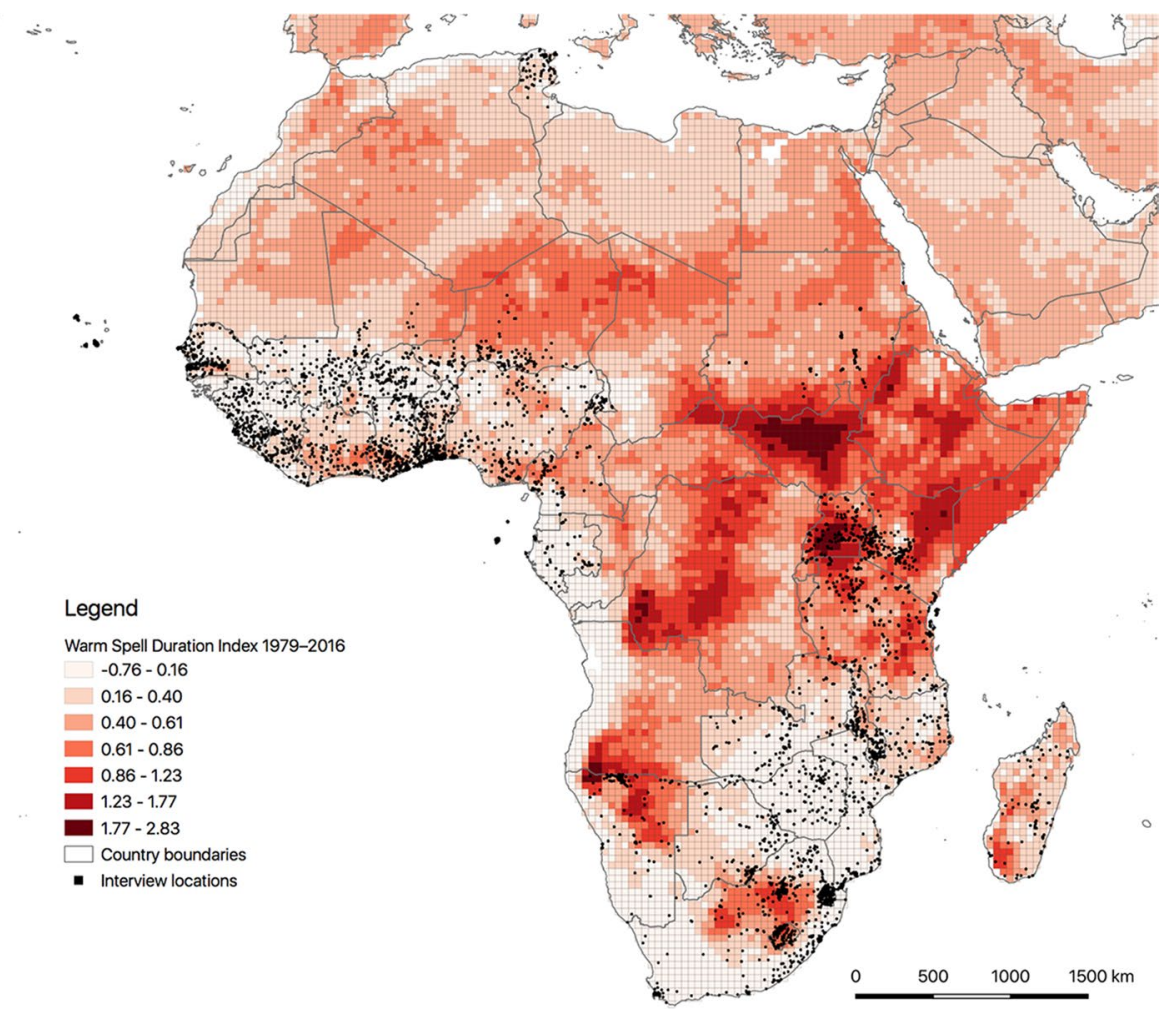

Fig. 1 Trends in warm spell durations and interview locations. Notes: The figure shows a map of Africa relating climate change data to interview locations. The shading corresponds to the annual trend (increases in days per year) in values of the Warm Spell Duration Index (WSDI) for the period 1979-2016 (ERA 5 data). The darker the shading of the grid cells, the stronger the increase in the number of at least six consecutive days with above-normal temperatures. Black markers indicate interview locations for the 7 th round of the Afrobarometer, conducted between September 2016 and September 2018

earlier decades, consistent with the notion of global warming. We exploit this variation to estimate the effect of climate variability on individual migration intentions (for a further contextual overview on environmental change and migration in Africa, see, e.g., Morrissey 2014; Brüning and Piguet 2018; Borderon et al. 2019).

To estimate the effect of climate change and climate change literacy on migration intentions, we estimate the following model:

$$
M I_{i, r}=\beta_{1} \text { TEMP }_{r}+\beta_{2} \text { CLIMLIT }_{i, r}+\beta_{3}\left(\text { TEMP }_{r} * \operatorname{CLIMLIT}_{i, r}\right)+\beta^{\prime} X_{i, r}^{\prime}+\varepsilon_{i, t}
$$

Using the OLS estimator, we explain migration intentions $(M I)$ of individual $i$ living in interview location $r$ by a measure of climate variability (TEMP), usually an indicator of rising temperatures, climate change literacy (CLIMLIT), and their interaction. We also account for a set of controls $(X)$ that include climate zone and year-month fixed effects and variables measuring individual characteristics of respondents (e.g., age, sex). Thus, our models compare migration intentions of individuals with different levels of 
climate change literacy within the same region after accounting for any country-specific and climate zone-specific effects and temporal trends.

We are primarily interested in the interaction effect of increasing temperatures and climate change literacy on migration intentions. This allows us to evaluate whether individuals with different climate change literacy levels respond differently to changing climate conditions. Summary statistics for all variables are reported in the Supplementary Tables S1a and S1b.

Climate data We employ a set of Climate Extreme Indices (CEIs), defined and developed by the Expert Team on Climate Change Detection and Indices (ETCCDI) and adopted by the World Meteorological Organization (WMO) (see Mistry, 2019; Zhang et al., 2011) for a full description of the CEIs). The calculation of CEIs at annual timescales requires daily measures of (i) maximum near-surface air temperature (Tmax, in ${ }^{\circ} \mathrm{C}$ ), (ii) minimum near-surface air temperature (Tmin, in ${ }^{\circ} \mathrm{C}$ ), and (iii) near-surface total precipitation (Precip, in $\mathrm{mm}$ ). We rely on the Warm Spell Duration Index (WSDI) as our principal measure. It measures the annual number of days in which the daily maximum temperature (Tmax) exceeds the 90th percentile of the long-term average Tmax for at least six consecutive days.

The input meteorological variables are drawn from the ERA5 global reanalysis data product at $0.25^{\circ}$ gridded resolution, made available by the European Center for MediumRange Weather Forecasts (ECMWF) through the Copernicus Climate Data Store. ${ }^{3}$ The CEIs are assembled using the WMO-recommended R software package "Climpact2." The CEIs employed in our study are further defined in Supplementary Table S2. In short, the CEIs in the econometric framework are operationalized as follows:

1. WSDI annual trend, 1979-2016: Trend in Warm Spell Duration Index, values 19792016

2. WSDI annual trend, 2009-2016: Trend in WSDI, values 2009-2016

3. WSDI change (2009-2016)-(1979-2008): Long-term difference in WSDI values, 20092016 average values minus 1979-2008 average values

4. WSDI 10-year average: 10-year average in WSDI, values 2007-2016

5. WSDI 3-year average: 3-year average in WSDI, values 2014-2016

6. HWM 10-year average: 10-year average in heat wave magnitude (Perkins and Alexander, 2013), values 2007-2016

7. SPEI 3-year average: 3-year average in Standardized Precipitation Evapotranspiration Index (Vicente-Serrano et al., 2010), values 2014-2016

Migration intention data The data comes from the 7th round of the Afrobarometer (2019), in which face-to-face interviews with a randomly selected sample of 1200 to 2400 respondents in 30 African countries were carried out between 2016 and 2018. For our analysis, this results in a sample of over 37,000 interviewed individuals. Using geo-coded information (longitude and latitude) provided by the Afrobarometer, we link each interview location in the Afrobarometer to the corresponding local climate data.

\footnotetext{
${ }^{3}$ Data accessed from https://cds.climate.copernicus.eu/cdsapp\#!/dataset/reanalysis-era5-single-levels?tab= overview on 20 May 2020.

${ }^{4}$ https://github.com/ARCCSS-extremes/climpact2
} 
We operationalize individuals' migratory responses as their migration intentions. Migration intentions are measured by considering respondents' answer to the following survey question: "How much, if at all, have you considered moving to another country to live?" Answer options are "Not at all" (coded 0), "A little bit," "Somewhat," and "A lot" (all coded 1); non-responses are dropped from the sample. Note that the survey specifically asks for international migration intentions; while domestic movements may also be a likely response to climate change, recent evidence suggests that the effect of environmental stress is particularly pronounced for the relative increase of intra-regional migratory behavior (Bekaert et al. 2021).

Climate literacy data We consider someone as climate literate if the survey respondent has heard of climate change and indicated that climate change means negative changes in the weather (such as more droughts, floods, or extreme heat) and/or thinks that climate change makes life in their country somewhat or much worse. Persons who are climate illiterate have never heard of climate change or think that it leads to positive changes in the weather or that it makes life in the country better due to changes in environmental conditions (see Table S1c in the Supplementary Material for question wordings). On average, $44 \%$ of our respondents are climate literate (see Table S1a in the Supplementary Material and also Selormey et al., 2019: 8, 12). The share of climate literacy varies between circa 26\% (Tunisia) and approximately $75 \%$ (Uganda).

As we show below, climate change literacy is highly correlated with general education. We, however, prefer to account for climate change literacy rather than education for three reasons. First, the education variable in the Afrobarometer dataset is a rather coarse measure of school degrees or length of school education that are difficult to compare across countries with different school systems. They also do not tell us anything about the content or the quality of education. Second, climate change literacy directly measures our theoretical construct, namely knowledge of climate change and its implications. While this knowledge might have been acquired in school, our measure helps us show that this knowledge is still available. Third, we may consider climate literacy as a means of correcting for a potential difference between meteorological reality and individual climate change perceptions. For instance, DeLongueville et al. (2020) show that changes in local rainfall are not necessarily reflected in rainfall perceptions among rural dwellers in Burkina Faso, arguing that subjective perceptions are influenced by additional (individual) factors (see also Niles and Mueller 2016).

However, we may expect climate literate individuals to be less subjective about climate change, making it easier for us to relate meteorological reality to the individual migratory response to climate change. Indeed, in Figure S1 in the Supplementary Material, we show that climate change literacy increases with rising temperature trends, where variation is substantial, especially in areas with higher WSDI levels. This supports the notion that climate literacy is linked to meteorological reality, while at the same time being-by construction-linked to individual climate change perception.

Controls Data on the control variables also come from the Afrobarometer (2019). In the baseline model, we control for age and gender. Here, controlling for age is especially necessary because respondents' age may correlate with both exposure to long-term climate change (e.g., older individuals are more likely to experience long-term changes) and migration intentions. We also consider a set of country fixed effects to account for economic and institutional differences between countries that may affect migration intentions as well 
as climate zone fixed effects to consider the differential role of increasing temperatures on human behavior in different climate zones. Here, we use the usual Köppen-Geiger climate classification system. Month-year fixed effects are included in some specifications to control for potential systematic differences in responses due to different interview periods.

Correlates of climate change literacy: model and variables Climate literates are not randomly distributed. Thus, besides comparing whether individuals who are knowledgeable about climate change have a different migratory response to it, we also want to understand which individuals are well informed about it in the first place. Therefore, we run additional OLS models with various fixed effects to identify individual socio-economic correlates of climate change literacy. These correlates, in turn, are expected to deepen our understanding of the nexus between climate change literacy and migration intentions under climate change.

We identify the various correlates of climate change literacy by considering the following model:

$$
\operatorname{CLIMLIT}_{i, r}=\beta_{1} \operatorname{CORR}_{i, r}+\beta^{\prime} X_{i, r}^{\prime}+\varepsilon_{i, t}
$$

Climate change literacy (CLIMLIT) is operationalized as explained above. The vector $\mathrm{X}$ includes the same fixed effects as defined for model 1. CORR refers to one of the following variables, which are all drawn from the Afrobarometer (2019):

1. News consumption: We differentiate between persons who get their news from any media (radio, television, newspapers, internet, or social media) every day, a few times a week, a few times a month, less than once a month, or never.

2. Profession: We consider individuals who are out of work (e.g., housewives, unemployed persons), farmers and agricultural workers, low-skilled service and industrial workers (traders, cleaners, domestic helps, laborers, etc.), students, and specialists (i.e., highskilled service and industrial workers, senior managers, teachers, lawyers, bureaucrats).

3. Education: We differentiate between no education, primary education, secondary education, and post-secondary education.

4. Location: We differentiate between rural and urban location.

\section{Empirical results}

We first investigate how local climate variability affects migration intentions and the extent to which this effect differs by levels of climate change literacy. The results are shown in Fig. 2 and in Table S3 in the Supplementary Material. ${ }^{5}$ We find that climate variability does not affect the migration intentions of individuals who are illiterate about it. By contrast, climate variability does lead to higher migration intentions among people who have heard of climate change and believe that it has negative effects. These effects hold for all five different measures of climate variability. Differences in the migratory response

\footnotetext{
5 As a robustness check, we also run ordinal logistic regression analyses as a way to account for the four response options of our dependent variable. The results remain the same as appears in Table S4 in the Supplementary Material.
} 


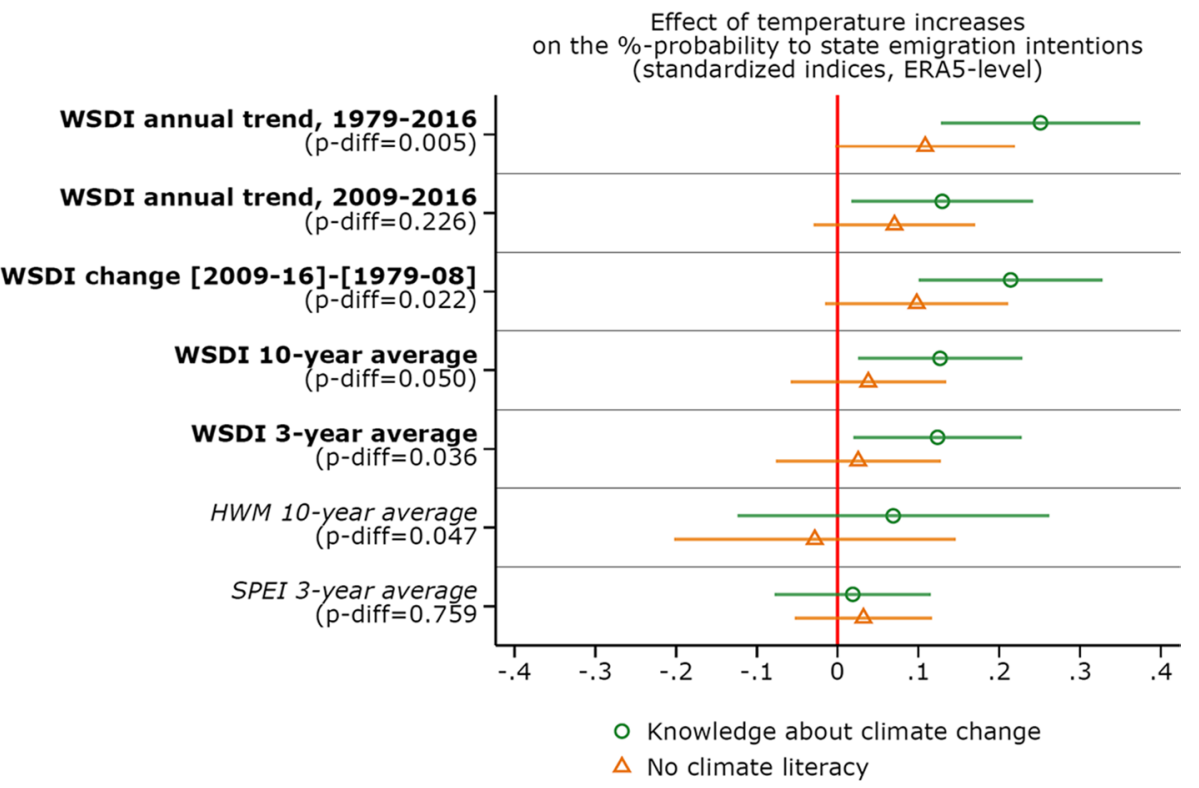

Fig. 2 Effect of climate change variables on migration intentions for climate literates and illiterates. Notes: Figure shows the impact of Climate Extreme Indices (CEIs), measured by different specifications of the Warm Spell Duration Index (WSDI), on migration intentions among climate literates and illiterates. Moreover, the effect of the 10-year average in heat wave magnitude (HWM) values (2007-2016) and the 3-year average in Standardized Precipitation Evapotranspiration Index values (2014-2016) are shown as robustness checks. The definitions of WSDI, HWM, and SPEI are provided in Table S2 in the Supplementary Material. WSDI 1979-2016 and 2009-2016 provide the longer- and shorter-term annual trend, WSDI (2009-2016)-(1979-2008) captures the long-term difference in warm spells, and WSDI 10- and 3-year average give the average number of exceptionally warm days over the last 10 and 3 years, respectively. Marginal effects after OLS regression reported. The $p$-value is associated with a series of Wald tests assessing whether there are differences in the effects if climate change on migration intentions between climate literate and illiterate respondents (null hypothesis: no difference). The associated regression table is reported in the Supplementary Material (Table S3). The graphs report point estimates and 95\% confidence intervals from seven distinct OLS models from Eq. (1). The underlying climate change variables are standardized to facilitate the presentation of the results. For all seven models, the dependent variable is an indicator of individual migration intentions that is either equal to zero (no intentions) or unity (at least some migration intentions). All seven models include country, climate zone, and year-month fixed effects. Individual age and sex are also controlled for. Standard errors to construct confidence intervals are clustered at the survey interview location

between climate-literate and -illiterate individuals are also usually statistically significant $(p<0.05)$. Thus, we can infer that climate change in the form of increasing temperatures does not increase the migration potential unless individuals are aware of the long-term consequences of climate change. ${ }^{6}$

\footnotetext{
${ }^{6}$ A possible objection to this conclusion is that this effect does not run via climate literacy but via education, given the potential positive correlation between climate literacy, education, and migration intentions. We therefore run a series of models where we also control for individual levels of education. Table S5 in the Supplementary Material shows that this does not affect our main result that climate change only increases migration intentions among the climate literate. Furthermore, and consistent with the existing literature, the findings in Table S5 also indicate that higher levels of education (independent of climate literacy effects) also positively correlate with migration intentions.
} 
Fig. 3 Correlates of climate change literacy. Notes: The figure shows the impact of different socio-economic indicators on climate change literacy. The graphs report the point estimates and 95\% confidence intervals from four distinct OLS models from Eq. (2). The associated regression table is reported in the Supplementary Material (Table S6). For all models, the dependent variable is a binary indicator of climate change literacy that is either equal to zero (no knowledge about climate change) or unity (individual knows about climate change, its nature, and consequences). All seven models include country, climate zone, and year-month fixed effects. Standard errors to construct confidence intervals are clustered by survey interview location

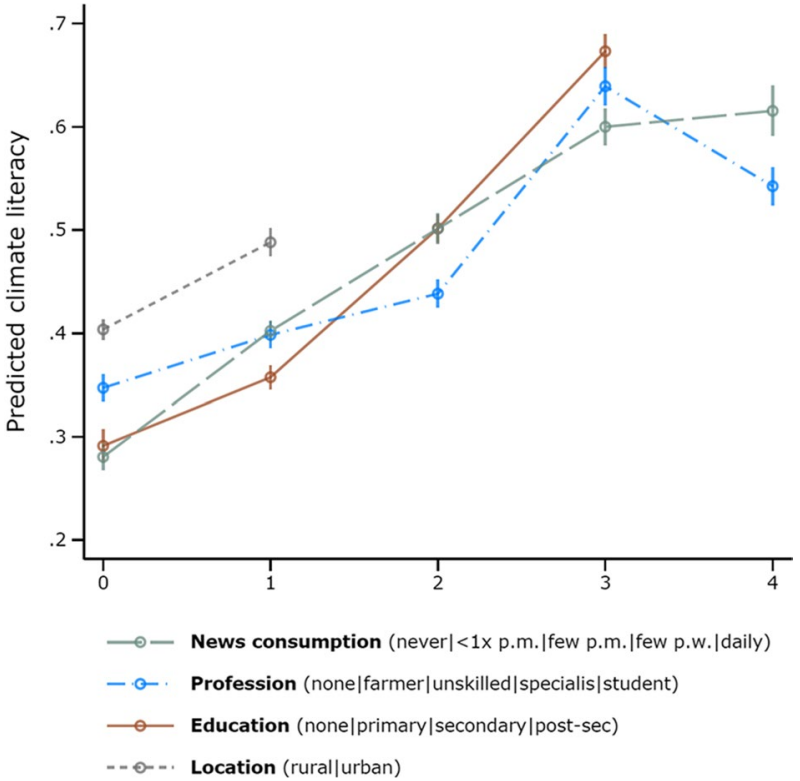

At the same time, we also show that there are no differences between the migratory responses of climate-literate and -illiterate respondents when we only look at the changes in drought conditions (SPEI) or the occurrence of heat waves (heat wave magnitude, HWM) rather than at long-run changes in local temperatures. That is, for both groups, variations in drought and heat wave patterns do not result in stronger migration intentions in statistically significant ways (see also Gray and Wise 2016; Kaczan and Orgill-Meyer 2020 for similar findings).

To better understand what socio-economic factors determine climate change literacy, we run a series of further regression models as described above. These findings are visualized in Fig. 3 (see also Table S6 in the Supplementary Material). The probability to possess knowledge about climate change and its negative consequences increases strictly monotonically with the respondents' level of education (purple solid line) and their news consumption (navy dashed line). Differences in occupation also explain differences in climate change literacy. For instance, our results indicate that farmers are rather uninformed about climate change, while students and specialists are most aware of it (blue dot-dashed line), which also holds for people in urban areas (khaki dashed line). Taken together with our earlier findings, these respondents are likely to react to climate change with stronger migration intentions. By contrast, we would expect no comparable migratory response from individuals who live in rural areas, have little access to news, have low formal education (at most primary education), and either are out of the workforce or work in agriculture or low-skilled jobs.

\section{Discussion and conclusion}

We examine the effect of climate change on the international migration intentions of over 37,000 individuals interviewed in 30 African countries. Our analysis yields three main results. First, climate change leads to stronger migration intentions only among 
individuals who are knowledgeable about the causes and (long term) impacts of climate change. Second, there is only a migratory response of climate literates when climate change is approximated by long-run increases in local temperatures, but not when operationalized as changing heat wave or drought patterns. Third, climate-literate respondents are more likely to live in urban areas, have high news consumption, are educated, and have demanding occupations (e.g., students and specialists).

These findings are in line with our theoretical expectations. That is, finding that climate change only consistently results in stronger migration intentions among climate literate individuals suggests that the effect of climate change on international migration intentions-and, ultimately, actual migration-is conditional on the understanding of climate change's broader implications and its irreversible long-term and unfavorable consequences. This effect appears to emerge via increasing temperatures rather than (changes in) precipitation. Potentially, this is because precipitation changes are primarily relevant to agriculture; farmers, in turn, tend to have especially low levels of climate literacy. By contrast, the migration-inducing effects of increasing temperatures tend to be more encompassing. For instance, Dell et al. (2012) show that rising temperatures (but not changes in precipitation) curtail economic growth. That is, temperature increase are expected to affect a wider range of socio-economic outcomes (e.g., employment, wages, health) for a wider group of individuals (who tend to be more climate literate), which makes it highly intuitive that temperature increases are especially likely to elicit a migratory response from climate literate individuals. For instance, the finding that migrants are better able to judge the extremeness of droughts compared to nonmigrants, as shown by Koubi et al. (2016c), is in line with this argument.

Our study is among the first to use individual-level data drawn from a large multicountry dataset to directly show how the effects of climate change on migration vary across different groups of people. Furthermore, to the best of our knowledge, we are the first to show that it is not enough to measure climate change objectively by established indicators (e.g., measures of moderate and severe extremes in climate, such as the WSDI, SPEI, and HWM), but that individual climate change literacy also needs to be considered. That is, our study emphasizes the role of cognitive capacities in understanding why individuals migrate.

Besides the necessity to account for climate change literacy-if possible-when examining the effect of climate variables on migration, our study has additional important implications for researchers and policymakers. Several country-level studies have shown that the effect of climate change on international migration is particularly pronounced in countries with relatively large agricultural sectors (e.g., Backhaus, 2015; Cai et al., 2016; Coniglio and Pesce, 2015; Dallmann and Millock, 2017). This has given rise to the argument that farmers may be especially responsive to global warming, e.g., because rising temperatures directly and adversely affect agricultural productivity and agricultural income. We show that this argument is misleading and likely due to the ecological fallacy. Rather, climate change literacy — which moderates the effect of climate change on migration-is especially low among farmers (see Niles and Mueller 2016 for climate change perceptions among farmers). That is, while climate change-induced out-migration may primarily originate from agriculture-dependent countries, our results do not indicate that it is particularly the farmers who respond to climate change. On the contrary, highly educated persons have a higher likelihood to migrate than those who are more directly affected by climate change. Consequently, when climate change leads to higher migration intentions among skilled individuals, this may further deprive affected countries of valuable talent. 
Supplementary Information The online version contains supplementary material available at https://doi. org/10.1007/s10584-021-03241-7.

Author contribution MH, DA, DM, and MS designed the study and wrote the paper. DA conducted most and $\mathrm{MH}, \mathrm{DM}$, and MS some of the analyses. MM processed the climate data. All contributed to editing the paper.

Funding Open Access funding enabled and organized by Projekt DEAL. Funding was provided by the Leibniz Association (Project IMPETUS, K36/2017) and the WZB Berlin Social Science Center. MM was supported by research funding from the European Research Council (ERC) under the European Union's Horizon 2020 research and innovation programme (grant agreement No. 756194, ENERGYA).

Data Availability Data replication sets are available here: https://doi.org/10.7910/DVN/3LRAFL

\section{Declarations}

Ethics approval This article does not contain any studies with human or animal participants performed by any of the authors.

Consent to participate According to the Afrobarometer webpage, interviews only proceeded after the respondents have given consent.

Competing interests The authors declare no competing interests.

Open Access This article is licensed under a Creative Commons Attribution 4.0 International License, which permits use, sharing, adaptation, distribution and reproduction in any medium or format, as long as you give appropriate credit to the original author(s) and the source, provide a link to the Creative Commons licence, and indicate if changes were made. The images or other third party material in this article are included in the article's Creative Commons licence, unless indicated otherwise in a credit line to the material. If material is not included in the article's Creative Commons licence and your intended use is not permitted by statutory regulation or exceeds the permitted use, you will need to obtain permission directly from the copyright holder. To view a copy of this licence, visit http://creativecommons.org/licenses/by/4.0/.

\section{References}

Abel G, Brottrager M, Cuaresma J, Muttarak R (2019) Climate, conflict and forced migration. Glob Environ Chang 54:239-249

Afrobarometer (2019). Afrobarometer Round 7 Geocoded Data. Available at http://www.afrobarometer.org.

Backhaus, A., Martinez-Zarzoso, I., Muris, C. (2015). Do climate variations explain bilateral migration? A gravity model analysis. IZA Journal of Migration 4(3). Online publication: https://doi.org/10. 1186/s40176-014-0026-3.

Bekaert E, Ruyssen I, Salomone S (2021) Domestic and international migration intentions in response to environmental stress: a global cross-country analysis. J Demogr Econ 87:383-436

Beine M, Parsons C (2015) Climatic factors as determinants of international migration. Scand J Econ 117:723-767

Berlemann M, Steinhardt MF (2017) Climate change, natural disasters, and migration: a survey of the empirical evidence. Cesifo Economic Studies 63:353-385

Borderon M, Sakdapolrak P, Muttarak R, Kebede E, Pagogna R, Sporer E (2019) Migration influenced by environmental change in Africa: a systematic review of empirical evidence. Demogr Res 41:491-544

Brüning, L., Piguet, E. (2018). Changements environnementaux et migration en Afrique de l'Ouest. Une revue des études de cas. Belgeo. Revue belge de géographie (1). Online publication: https://journ als.openedition.org/belgeo/28836 (accessed 9 July 2021).

Buyondo, D. (2021). Why We May Never See L. Kijjanebarola Again. New Vision. August 8.

Cai R, Feng S, Oppenheimer M, Pytlikova M (2016) Climate variability and international migration: the importance of the agricultural linkage. J Environ Econ Manag 79:135-151 
Carter C, Cui X, Ghanem D, Mérel P (2018) Identifying the economic impacts of climate change on agriculture. Annu Rev Resour Econ 10:361-380

Cattaneo C, Beine M, Fröhlich CJ, Kniveton D, Martinez-Zarzoso I, Mastrorillo M, Millock K, Piguet E, Schraven B (2019) Human migration in the era of climate change. Rev Environ Econ Policy 13:189-206

Cattaneo C, Peri G (2016) The migration response to increasing temperatures. J Dev Econ 122:127-146

Coniglio ND, Pesce G (2015) Climate variability and international migration: an empirical analysis. Environ Dev Econ 20:434-468

Dallmann I, Millock K (2017) Climate variability and inter-state migration in India. Cesifo Econ Stud 63(4):560-594

Dell M, Jones BF, Olken BA (2012) Temperature shocks and economic growth: evidence from the last half century. Am Econ J Macroecon 4:66-95

Delli Carpini MX, Keeter S (1996) What Americans know about politics and why it matters. Yale University Press, New Haven, CT

DeLongueville F, Ozer P, Gemenne F, Henry S, Mertz O, Nielsen J (2020) Comparing climate change perceptions and meteorological data in rural West Africa to improve the understanding of household decisions to migrate. Clim Change 160:123-141

Docquier F, Peri G, Ruyssen I (2014) The cross-country determinants of potential and actual migration. Int Migr Rev 48:37-99

Galston WA (2001) Political knowledge, political engagement and civic education. Annu Rev Polit Sci 4:217-234

Gray C, Wise E (2016) April 01). Country-specific effects of climate variability on human migration. Clim Change 135:555-568

Haines A, Kovats SR, Campbell-Lendrum DH, Corvalan CF (2006) Climate change and human health: impacts, vulnerability and public health. Public Health 120:585-596

Intergovernmental Panel on Climate Change [IPCC]. 2014. Climate change 2014 synthesis report. Available at http://www.ipcc.ch/ (accessed 23 February 2021).

Kaczan D, Orgill-Meyer J (2020) The impact of climate change on migration: a synthesis of recent empirical insights. Clim Change 158:281-300

Kasumba, G. (2020). Integrate climate change studies into curricula. Daily Monitor. January 13.

Kenyatta, U. (2021). Climate change is a risk factor to Africa's security, President Kenyatta Says. The Standard. March 9.

Koubi V, Spilker G, Schaffer L, Böhmelt T (2016a) The role of environmental perceptions in migration decision-making: evidence from both migrants and non-migrants in five developing countries. Popul Environ 38:134-163

Koubi V, Spilker G, Schaffer L, Bernauer T (2016b) Environmental stressors and migration: evidence from Vietnam. World Dev 79:197-210

Koubi V, Stoll S, Spilker G (2016c) Perceptions of environmental change and migration decisions. Clim Change 138:439-451

Lu M (1999) Do people move when they say they will? Inconsistencies in individual migration behavior. Popul Environ 20:467-488

Lungu, E. (2019). Zambia : full address by President Edgar Lungu to Parliament on National Values and Principles. Lusaka Times. March 15.

Mach KJ, Kraan CM, Adger WN, Buhaug H, Burke M, Fearon JD, Field CB, Hendrix CS, Maystadt J-F, O’Loughlin J, Roessler P, Scheffran J, Schultz KA, von Uexkull N (2019) Climate as a risk factor for armed conflict. Nature 571:193-197

Marchiori L, Maystadt JF, Schumacher I (2012) The impact of weather anomalies on migration in subSaharan Africa. J Environ Econ Manag 63:355-374

Marquis L (2010) Understanding political knowledge and its influence on voting preferences in the 2007 federal election. Swiss Political Sci Rev 16:425-456

Maurel M, Tuccio M (2016) Climate instability, urbanization and international migration. J Dev Stud 52:735-752

Meierrieks, D. (2021). Weather shocks, climate change and human health. World Development 138: 105228.

Mistry MN (2019) A high-resolution global gridded historical dataset of climate extreme indices. Data $4: 41$

Morrissey J (2014) Environmental change and human migration in Sub-Saharan Africa. In: Piguet E, Laczko F (eds) People on the Move in a Changing Climate: The Regional Impact of Environmental Change on Migration. Springer, Netherlands, pp 81-109 
Niles M, Mueller N (2016) Farmer perceptions of climate change: associations with observed temperature and precipitation trends, irrigation, and climate beliefs. Glob Environ Chang 39:133-142

Nyasimi, M., Radeny, M. AO., Mungai, C., Kamini, C. (2016). Uganda's National Adaptation Programme of Action: implementation, challenges and emerging lessons. Copenhagen, Denmark: CGIAR Research Program on Climate Change, Agriculture and Food Security (CCAFS).

Perkins SE, Alexander LV (2013) On the measurement of heat waves. J Clim 26:4500-4517

Selormey, E.E., Zupork Dome, M., Osse, L., Logan, C. (2019). Change ahead: experience and awareness of climate change in Africa. Afrobarometer Policy Paper No. 60.

Tjaden J, Auer D, Laczko F (2019) Linking migration intentions with flows: evidence and potential use. Int Migr 57:36-57

Vesco P, Kovacic M, Mistry M, Croicu M (2021) Climate variability, crop and conflict: exploring the impacts of spatial concentration in agricultural production. J Peace Res 58:98-113

Vicente-Serrano SM, Begueria S, Lopez-Moreno JI (2010) A multiscalar drought index sensitive to global warming: The Standardized Precipitation Evapotranspiration Index. J Clim 23:1696-1718

Zhang X, Alexander L, Hegerl GC, Jones P, Tank AK, Peterson TC, Trewin B, Zwiers FW (2011) Indices for monitoring changes in extremes based on daily temperature and precipitation data. Wires Clim Change 2:851-870

Publisher's Note Springer Nature remains neutral with regard to jurisdictional claims in published maps and institutional affiliations. 